\title{
BMJ Open Medical school selection criteria as predictors of medical student empathy: a cross-sectional study of medical students, Ireland
}

\author{
Donnchadh M O'Sullivan, ${ }^{1}$ Joseph Moran, ${ }^{2}$ Paul Corcoran, ${ }^{3}$ Siun O'Flynn, \\ Colm O'Tuathaigh, ${ }^{1}$ Aoife M O'Sullivan ${ }^{1}$
}

To cite: O'Sullivan DM, Moran J, Corcoran P, et al. Medical school selection criteria as predictors of medical student empathy: a crosssectional study of medical students, Ireland. BMJ Open 2017;0:e016076. doi:10.1136/ bmjopen-2017-016076

- Prepublication history for this paper is available online. To view these files please visit the journal online (http://dx.doi org/10.1136/bmjopen-2017016076).

Received 4 March 2017 Revised 28 May 2017

Accepted 5 June 2017

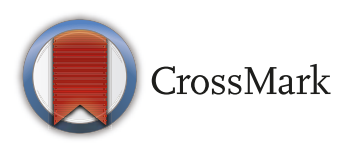

${ }^{1}$ School of Medicine, University College Cork, Brookfield Health Sciences Complex, Cork, Ireland ${ }^{2}$ Department of General Practice, Western Gateway Building, University College Cork, Cork, Ireland

${ }^{3}$ Department of Epidemiology and Public Health, Western Gateway Building, University College Cork, Cork, Ireland

Correspondence to

Dr Aoife M 0'Sullivan;

aoifemos89@gmail.com

\section{ABSTRACT}

Objectives To determine whether performance in any of the Health Professions Admissions Test (HPAT) sections, most specifically the interpersonal understanding section, correlates with self-reported empathy levels in medical students.

Setting The study was conducted in University College Cork, Ireland.

Participants 290 students participated in the study. Matching HPAT scores were available for 263 students. All male and female undergraduate students were invited to participate. Postgraduate and international students were excluded.

Primary and secondary outcome measures Primary measures: HPAT-Ireland and Jefferson Scale of Physician Empathy (JSE) scores were compared including subsection analysis. Secondary measures: comparisons were made between groups such as gender and year of programme. Results A total of 290 students participated. Males scored significantly higher than females for total HPATIreland $(\mathrm{U}=7329, \mathrm{z}=-2.04, \mathrm{p}<0.05)$, HPAT-Ireland section $1(U=5382, z=-5.21, p<0.001)$ and section 3 scores $(U=6833, z=-2.85, p<0.01)$. In contrast, females scored significantly higher than males on HPAT-Ireland section $2(\mathrm{U}=5844, \mathrm{z}=-4.46, \mathrm{p}<0.001)$. Females demonstrated significantly higher total JSE scores relative to males (mean score \pm SEM: $113.33 \pm 1.05$ vs 109.21 \pm 0.95 ; $\mathrm{U}=8450, \mathrm{z}=-2.83, \mathrm{p}<0.01$ ). No significant association was observed between JSE scores and any of the HPAT-Ireland measures (all $p>0.05$ ). There was no effect of programme year on JSE scores (all $p>0.05$ ).

Conclusion The introduction of the HPAT-Ireland test was partly designed to identify students with strong interpersonal skills. A significant finding of this study is that JSE values did not correlate with HPAT-Ireland scores. This study suggests no clear link between scores on a selection test, the HPAT-Ireland, which is designed to assess several skill domains including interpersonal skills, and scores on a psychometric measure of empathy, at any point during medical education.

\section{INTRODUCTION}

Empathy is regarded as one of the most important competencies required by health professionals and is considered an important

\section{Strengths and limitations of this study}

- The results of this study add to the body of research in the area of medical entrance methods, particularly in Ireland.

- The use of a widely used, reliable tool, the Jefferson Scale of Physician Empathy (JSE) as a measure of empathy strengthens the results of this study.

- Use of a longitudinal assessment of JSE scores would provide a more valid approach to the questions of whether there is an empathy decline across years spent in medical school

- The response rate varied across the various year groups, ranging from $50 \%$ to $74 \%$, increasing the possibility of response-rate bias.

focus of medical education curricula. ${ }^{12}$ Physician empathy has been positively correlated with better patient comprehension, ${ }^{3}$ more accurate diagnosis, ${ }^{4}$ increased treatment adherence, ${ }^{5}$ and decreased emotional distress and improved quality of life among patients. ${ }^{67}$ It has been proposed that empathy is not a unitary concept and that it is highly influenced by contextual factors in practice. ${ }^{8}$ The Jefferson Scale of Physician Empathy (JSE) is an instrument which has been developed and employed to measure the empathy levels of healthcare professionals. ${ }^{19}$ Explanatory factor analysis of the scale suggests a multidimensional construct comprising three factors: 'perspective-taking', 'compassionate care' and 'standing (walking) in patient's shoes'. ${ }^{910}$ A more recent analysis of the factor structure of the JSE scale suggested an additional fourth factor, 'metacognitive effort', which measures the level of insight possessed by the student regarding the need to think like the patient. ${ }^{1}$ It is, at present, unclear which of these factors is more strongly associated with improved patient outcomes. 
Research in medical education has primarily employed the JSE instrument to demonstrate a strong relationship between empathy levels and ratings of clinical competence in medical students and trainees. ${ }^{112}$ Empathy levels have also been linked to motivation to study medicine ${ }^{13}$ as well as increased peer ratings in relation to professionalism ${ }^{14}$ and leadership ${ }^{15}$ among medical students. Empathy has also been shown to be moderately associated with intention to pursue a career in a people-oriented rather than a procedure-oriented specialty after graduation. ${ }^{16}{ }^{17}$ Another notable finding reported in the medical student empathy literature concerns the reported decline in empathy during undergraduate training; ${ }^{18}$ however, Costa et $a l^{19}$ argue this decline has been linked with diminution in the quality of healthcare provision and is likely attributable to a constellation of factors including elements of the hidden curriculum and inadequate role models. In light of data linking physician and student empathy with better clinical performance, empathy has been defined as an important graduate outcome for undergraduate curricula in USA and Canada. ${ }^{202}$ Guidelines for teaching professionalism within the undergraduate curriculum in Ireland and the UK have also tried to incorporate the concept of empathy. ${ }^{22}$

There is considerable diversity in the methods used in medical school admission and selection. While academic achievement is a heavily weighted selection criterion, specialised aptitude tests are also widely used internationally. ${ }^{23}$ In the literature on medical school selection practices, there has also been some discussion about the utility of methods such as the situational judgement test for assessing non-academic attributes including empathy which are considered important within the profession. ${ }^{24} 25$ Since 2009, the Irish medical school application process ranks applicants on the basis of secondary level grades as well as performance in the Health Professions Admission Test-Ireland (HPAT-Ireland), which shares a similar structure to the Undergraduate Medicine and Health Sciences Admission Test (UMAT), used in Australia and New Zealand. HPAT-Ireland was introduced with the intention of broadening access to medical school, increased emphasis on non-academic attributes and bringing Irish medical schools' recruitment policy in line with international norms. ${ }^{26}$ A 2006 national educational report entitled 'Medical Education in Ireland-A New Direction', recommended a more diverse entry mechanism to medical education in Ireland and proposed that an alternative mechanism 'must still ensure that students selected have the intellectual and emotional capability for a demanding course and profession'. ${ }^{27}$ The HPAT tool was noted to be reliable and valid by the National Evaluation group. ${ }^{28}$ Information about the development of the various test items is not readily available. This has previously been noted by a study relating to Irish medical school entry mechanisms. ${ }^{26}$

The HPAT contains three separate sections: logical reasoning and problem-solving (analysis of graphically presented information), interpersonal understanding (demonstrating awareness of thoughts, feeling and intentions of scenario characters) and non-verbal reasoning (pattern shape detection and sequence prediction).

Predictive validity of any selection test is its ability to predict subsequent performance in medical school. Previous research has shown that HPAT scores were a poor predictor of clinical or communication skills performance. ${ }^{26}$ In the current study, we sought to determine whether performance in any of the HPAT sections, but perhaps most specifically the interpersonal understanding section, would correlate with self-reported empathy levels in undergraduate medical students.

\section{METHODS}

\section{Study design and procedure}

A cross-sectional design was employed in the present study. The sample consisted of a cohort of medical students across years 1-5 of the undergraduate medical programme, who had sat the HPAT selection test prior to obtaining a place in medical school. Paper-based questionnaires were distributed to all year groups during lectures during the academic year 2014/2015. All students who had sat the HPAT examination were invited to participate, thereby excluding all international students and students registered on the graduate-entry medical programme. Student registration numbers were used to obtain HPAT scores from the university database.

Questionnaires were provided to students at the beginning of a lecture and collected after the end of the lecture. There was no incentive to complete the questionnaire. Data pertaining to gender, age, year of programme and year HPAT was undertaken were collected. Desired future career specialty was also noted, but the responses were more incomplete and these data were not analysed or reported. For the purpose of the analysis, students not present in class on the day were also considered non-responders to the questionnaire.

\section{Study instruments}

Empathy was evaluated using the student version of the Jefferson Scale of Physician Empathy-JSE-S. ${ }^{10}$ This self-report survey tool includes 20 items rated on a 7-point Likert-type scale with anchors 1: Strongly disagree and 7: Strongly agree. It has been widely used for the study of empathy in clinicians and in medical students. ${ }^{10}$

The JSE has been shown to be internally consistent ${ }^{29}$ and to have been positively correlated with ratings of clinical competence. ${ }^{11}$ The student version of the JSE, which was used in this study, has been shown to be reliable. ${ }^{30}$ The JSE was significantly and positively correlated with sociability subscale scores of the Zuckerman-Kuhlman Personality Questionnaire. ${ }^{16}$

All candidates who sit HPAT-Ireland sign a waiver allowing their results to be analysed for research purposes. The study was approved by the Clinical Research Ethics Committee of the Cork Teaching Hospitals. 


\section{Data analysis}

All data were entered into and analysed using SPSS version 21.0 for Windows (SPSS, Chicago, Illinois, USA). Descriptive statistics, mean, SEM and median (where appropriate) were used to describe continuous variables and frequencies to describe categorical variables. Mann-Whitney $U$ tests and one-way analysis of variance (ANOVA) were employed to compare HPAT-Ireland and JSE scores between groups (eg, gender, year of programme). Pearson's correlation coefficient analysis was employed to examine the relationship between continuous baseline and outcome variables. A correlation coefficient of $\geq 0.20$ or $\leq-0.20$ was defined as a threshold for scientific significance. Multiple linear regression analysis was used to identify significant predictors of JSE score variation in the present sample.

\section{RESULTS}

\section{Demographics}

A total of 290 students participated in this study, providing a response rate of $59.2 \%(290 / 490)$. Of this sample, $53.4 \%(n=155)$ were female and distributed across the following age (years) categories: 17-21 (51\%), 22-24 $(44.8 \%),<24(4.2 \%)$. The dataset included HPAT-Ireland scores collected between 2009 and 2014, in a student sample across years 1-5 of the undergraduate programme (year $1: \mathrm{n}=68,71 \%$; year $2: \mathrm{n}=45,45 \%$; year 3: $n=50,49 \%$; year $4: n=59,59 \%$; year $5: n=68,74 \%)$. Of the 290 surveys collected, matching HPAT scores were available for 263 students, which was the final sample size available for correlational and/or regression analyses. One-way ANOVA examined the influence of year in which HPAT was taken on both total score and individual HPAT section values and revealed a significant main effect for the factor 'year' for total HPAT-Ireland score $(\mathrm{F}(5,257)=13.16, \mathrm{p}<0.001)$, HPAT-Ireland section 1 (logical reasoning and problem-solving) $(\mathrm{F}(5,257)$ $=3.71, \mathrm{p}<0.01)$, section 3 (non-verbal reasoning) $(\mathrm{F}(5$, $257)=19.67, \mathrm{p}<0.001)$, but not HPAT-Ireland section 2 (interpersonal understanding) scores $(\mathrm{p}>0.05)$. Posthoc Bonferroni analyses confirmed that HPAT-Ireland total and HPAT-Ireland section 3 were significantly lower in 2014 relative to all years between 2010-2013 inclusive $($ all $\mathrm{p}<0.05)$ and the same pattern was observed for the year 2010, where HPAT-Ireland total and HPAT-Ireland section 3 scores were significantly lower than comparable 2012-2014 values (all $\mathrm{p}<0.05$ ).

\section{HPAT-Ireland and JSE scores: relationship with demographic and educational variables}

Descriptive statistics for HPAT-Ireland and JSE variables are outlined in table 1 . Males scored significantly higher than females for total HPAT-Ireland ( $\mathrm{U}=7329, \mathrm{z}=-2.04$, $\mathrm{p}<0.05$ ), HPAT-Ireland section 1 (logical reasoning and problem-solving) $(\mathrm{U}=5382, \mathrm{z}=-5.21, \mathrm{p}<0.001)$ and section 3 (non-verbal reasoning) scores $(\mathrm{U}=6833, \mathrm{z}=-2.85, \mathrm{p}<0.01)$. In contrast, females scored significantly higher than males on HPAT-Ireland section 2 (interpersonal understanding) $(\mathrm{U}=5844, \mathrm{z}=-4.46, \mathrm{p}<0.001)$. Females demonstrated significantly higher total JSE scores relative to males (mean score \pm SEM: $113.33 \pm 1.05$ vs $109.21 \pm 0.95$; $U=8450$, $\mathrm{z}=-2.83, \mathrm{p}<0.01)$. One-way ANOVA comparisons revealed no effect of programme year on JSE scores $(p>0.05$; table 1).

HPAT-Ireland and JSE scores: results of correlational analyses Table 2 provides a summary of the results of the correlational analyses. A weak but statistically significant positive correlation was observed between HPAT-Ireland section 3 (non-verbal reasoning) scores and HPAT-Ireland section 1 (logical reasoning and problem-solving) $(\mathrm{r}=0.21, \mathrm{p}<0.05)$. A weak but statistically significant negative correlation was observed between HPAT-Ireland section 3 scores and HPAT-Ireland section 2 (interpersonal understanding) $(\mathrm{r}=-0.20, \mathrm{p}<0.05)$. Unsurprisingly, HPAT-Ireland total scores strongly correlated with each section subscore: HPAT-Ireland section $1(\mathrm{r}=0.67, \mathrm{p}<0.0001)$, HPAT-Ireland section $2(\mathrm{r}=0.43, \mathrm{p}<0.001)$ and HPAT-Ireland section 3 $(\mathrm{r}=0.58, \mathrm{p}<0.001)$. No significant association was observed between JSE scores and any of the HPAT-Ireland measures (all p>0.05; table 2).

\section{Multiple regression analysis}

Multiple regression analysis was undertaken to investigate the nature of the relationship between empathy, HPAT scores and demographic or educational variables (gender and year of programme). Table 3 provides a summary of the factors affecting JSE score variation in the present sample. Consistent with the correlational analysis, none of the selected variables emerged as a significant predictor of medical student empathy. Tables 4 and 5 depict the gender analysis.

Table 1 Descriptive statistics for the variables of interest

\begin{tabular}{llll}
\hline Variable & N & M (SEM) & Median \\
\hline HPAT-Ireland section 1: logical reasoning and problem-solving (Max=100) & 263 & $61.31(0.47)$ & 61.0 \\
HPAT-Ireland section 2: interpersonal understanding (Max=100) & 263 & $59.21(0.46)$ & 59.0 \\
HPAT-Ireland section 3: non-verbal reasoning (Max=100) & 263 & $66.12(0.52)$ \\
Total HPAT-Ireland (Max=300) & 263 & $184.93(16.0)$ & 185.0 \\
Total JSE (Max=140) & 290 & $111.42(0.72)$ & 112.0 \\
\hline
\end{tabular}

HPAT-Ireland, Health Professions Admissions Test-Ireland; JSE, Jefferson Scale of Physician Empathy; M, mean. 
Table 2 Correlations between HPAT-Ireland and JSE scores

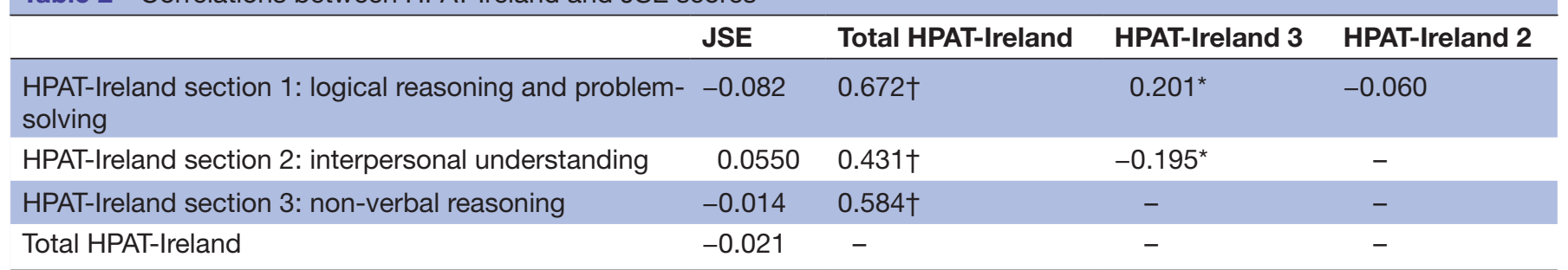

Correlation coefficients correspond to results of Pearson's $r$ analysis.

${ }^{*} \mathrm{p}<0.05$.

$\mathrm{tp}<0.001$.

HPAT-Ireland, Health Professions Admissions Test-Ireland; JSE, Jefferson Scale of Physician Empathy.

\section{DISCUSSION}

The introduction of the new entry mechanism for medical school to Ireland, via completion of the HPAT-Ireland test was partly designed to identify students with strong interpersonal skills, who would be able to demonstrate empathy as future clinicians. These results, which have failed to show any association between selection test scores (including subscales designed to measure interpersonal understanding) and individual variation on a psychometric measures of empathy, adds to a growing literature questioning the validity of the HPAT-Ireland test as a selection tool. For example, Quinn and colleagues ${ }^{31}$ administered a modified version of the HPAT-Ireland to a sample of hospital consultants, non-consultant hospital doctors and medical students. They reported no group differences in test performance, suggesting that increased clinical experience is uncorrelated with what is assessed across the three sections of this selection tool. A more recent study examined the relationship between HPAT-Ireland scores and communication and clinical skills subtest scores in a Year 1 Objective Structured Clinical Examination. ${ }^{26}$ These authors also reported no relationship between selection test scores and scores for either subtest.

\section{HPAT-Ireland and JSE scores: gender differences}

The present study demonstrated that males scored significantly higher than females on HPAT subsections 1 (logical reasoning and problem-solving) and 3 (non-verbal reasoning). Existing published evidence has demonstrated that there are slight gender differences in total HPAT-Ireland scores, generally favouring males but varying from year to year. ${ }^{32}$ Similar gender differences have been reported in relation to other medical schools selection tests, for example, UK Clinical Aptitude Test (UKCAT), Medical College Aptitude Test (MCAT), UMAT. ${ }^{33} 34$ With respect to specific subsection score differences, the present results are in agreement with previous data which have shown that males perform better on measures of non-verbal reasoning, while females score higher on items measuring interpersonal understanding. ${ }^{35-37}$ Women consistently score higher than men in relation to JSE scores. ${ }^{1011}$ In this study, females also scored higher than males using the JSE-S scale.

\section{JSE scores and evidence for decline of empathy in medical school}

The results of the present cross-sectional analysis demonstrated that JSE values did not vary significantly across the curriculum. Specifically, total JSE scores were comparable among both students who had recently entered and those at the point of exit from the undergraduate programme. Earlier studies have shown erosion of empathy in medical school, ${ }^{18} 38$ particularly during the transition from the preclinical to the clinical cycle; this has been attributed to several factors, including lack of role models, high academic workload, time pressure. ${ }^{38}$ However, the present results are in agreement with the conclusions arising from a review of 11 longitudinal studies which interrogated changes in self-reported empathy levels in students at various stages of medical training. ${ }^{39}$ This review concluded that there was no definitive evidence to suggest that empathy levels declined during medical education and that studies purporting to show such deficits were compromised by inappropriate conceptualisation and measurement of empathy (ie, self-report measures including the JSE) in a patient care context. This explanation does not fully explain the current study results (ie, lack of association between HPAT-Ireland and empathy), where the JSE measure was also employed. Rather, the absence of an empathy decline may represent students' increasing awareness of the recent emphasis placed by professional bodies including the Irish Medical Council on the importance of empathy and compassion in the development of professionalism. ${ }^{22}$

\section{HPAT-Ireland and criterion validity}

An ability to communicate with patients and understand their concerns is considered important when assessing global clinical competence. JSE scale scores have been shown to be positively correlated with ratings of clinical competence. ${ }^{11}$ Other instruments for measuring empathy such as the Interpersonal Reactivity Index (IRI), ${ }^{40} 41$ were reported to have modest relationships with the JSE scores among medical students. ${ }^{42}$ In a study involving medical students, it was reported that the scores of the JSE were significantly and positively correlated with sociability subscale scores of the Zuckerman-Kuhlman 


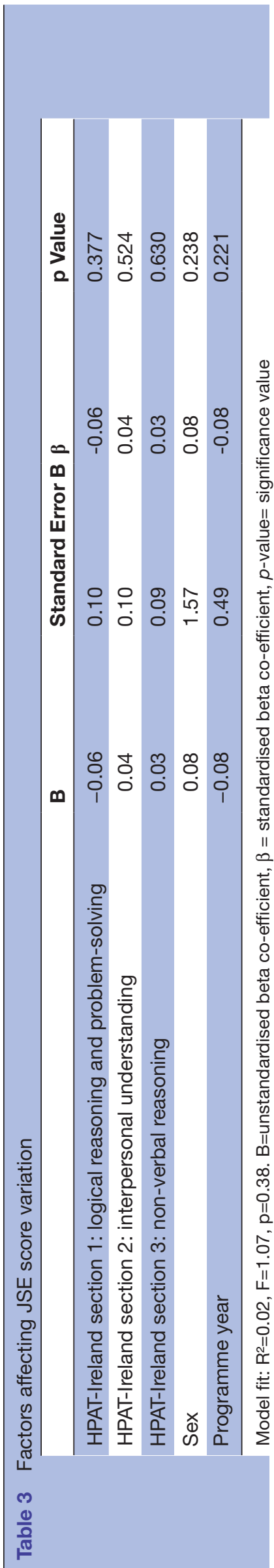

Personality Questionnaire. ${ }^{16}$ Therefore, when reflecting on the observed lack of association between HPAT and JSE scores, the criterion validity (which reflects the extent to which a measure is related to an outcome) of the HPAT-Ireland test must be questioned. In a recent review of the construct validity of HPAT-Ireland, it was noted that criterion validity is a major question mark for more recently devised selection tests including HPAT-Ireland's performance. ${ }^{43}$ These authors suggested that selection tests containing more science-related, knowledge-based items, such as MCAT, may be more predictive in relation to the early years of the undergraduate programme, where there is a greater focus on biomedical sciences. In contrast, they propose that HPAT-Ireland, which assesses a broader range of reasoning and interpersonal skills, may be more predictive in the clinical years. ${ }^{43}$

\section{Study limitations}

One of the limitations of the present study is the use of a cross-sectional design in a single educational institution and therefore may not be representative of the national experience. Use of a longitudinal assessment of JSE scores would provide a more valid approach to the questions of whether there is an empathy decline across years spent in medical school. Additionally, the response rate varied across the various year groups, ranging from $50 \%$ to $74 \%$, increasing the possibility of response bias. Data pertaining to the non-responders were not collected or analysed and therefore it is not evident if this group would vary significantly from those studied. Selection bias could exist in this study given that convenience sampling during lectures was used. It is possible that an increased response rate or the analysis and comparison of data related to non-responders could have potentially affected the results of the study.

All measures of empathy, including the JSE, are at best a proxy of empathic behaviour. It might also be argued items in the JSE are transparent and thus susceptible to social desirability response bias, that is, they could be answered in a way that is recognised as more socially acceptable. However, the JSE was administered in 'non-penalising' situation where the purpose was described as research. Respondents were assured that their responses would be confidential and would be used only for research purposes approved by the Research Ethics Committee. This assurance, in itself, may reduce respondents' tendency to give socially desirable responses. The developers of JSE scale note that 'the pattern of relationships in their validity studies, particularly the convergent and discriminant validities, suggests that social desirability response bias, even if operative, did not substantially distort the expected relationships' ${ }^{10}$ These authors also conducted a study to investigate the influence of faking 'good' responses on JSE scores. ${ }^{16}$ In that study, they administered the S-Version of the JSE and other personality tests, including the ZKPQ to 422 first-year medical students who matriculated at Jefferson Medical College. Analysis of covariance was employed to control the effect of giving false responses 
Table 4 Gender analysis (female)

\begin{tabular}{llllll}
\hline & & JSE total & HPAT total & HPAT 3 & HPAT 2 \\
\hline HPAT section 1 & Pearson's correlation & -0.079 & $0.701 \dagger$ & $0.246 \dagger$ & -0.004 \\
& $\mathrm{p}$ Value & 0.346 & 0 & 0.003 & 0.965 \\
HPAT section 2 & $\mathrm{N}$ & 143 & 143 & 143 & 143 \\
& Pearson's correlation & 0.124 & $0.463 \dagger$ & $-0.261 \dagger$ & \\
HPAT section 3 & $\mathrm{p}$ Value & 0.142 & 0 & 0.002 & \\
& $\mathrm{~N}$ & 143 & 143 & 143 & \\
& Pearson's correlation & -0.04 & $0.543^{* *}$ & & \\
HPAT total & $\mathrm{p}$ Value & 0.639 & 0 & \\
& $\mathrm{~N}$ & 143 & 143 & & \\
& Pearson's correlation & 0.004 & & & \\
& $\mathrm{p}$ Value & 0.963 & & & \\
& $\mathrm{~N}$ & 143 & & & \\
& & & & & \\
& & & & & \\
\end{tabular}

Correlation coefficients correspond to results of Pearson's $r$ analysis.

${ }^{*} p<0.05$.

$\mathrm{tp}<0.001$.

HPAT, Health Professions Admissions Test; HPAT-Ireland section 1, logical reasoning and problem-solving; HPAT-Ireland section 2 , interpersonal understanding; HPAT-Ireland section 3, non-verbal reasoning; JSE, Jefferson Scale of Physician Empathy.

on the research outcomes, using the 'infrequency' score as a covariate, and they reported no substantial change in the general pattern of results. These findings suggest that social desirability response bias does not distort the validity of the JSE score.

A recent study comparing the JSE and the IRI, another widely used empathy scale, across students in five countries, showed weak correlation between these two scores. This article concluded that these scales measure different constructs of empathy. ${ }^{44}$ The relationship between the HPAT and IRI has not been assessed, and there is no readily available data from the manufacturers of the construct of the HPAT.

\section{CONCLUSION}

In a systematic review of the literature regarding use of empathy tests in medicine, it was concluded that while evidence of reliability, internal consistency and validity were observed for several instruments, no existing empathy measure was regarded as sufficiently reliable and valid for pretraining admission selection. ${ }^{45}$ While

\begin{tabular}{llllll}
\hline Table 5 Gender analysis (male) & & & & \\
\hline & & JSE total & HPAT total & HPAT 3 & HPAT 2 \\
\hline HPAT section 1 & Pearson's correlation & -0.02 & $0.653 \dagger$ & 0.079 & 0.069 \\
& $\mathrm{p}$ Value & 0.828 & 0 & 0.392 & 0.452 \\
& $\mathrm{~N}$ & 120 & 120 & 120 & 120 \\
HPAT section 2 & Pearson's correlation & -0.104 & $0.507 \dagger$ & -0.047 & \\
& $\mathrm{p}$ Value & 0.256 & 0 & 0.61 & \\
HPAT section 3 & $\mathrm{~N}$ & 120 & 120 & 120 & \\
& Pearson's correlation & 0.051 & 0.611 & & \\
& $\mathrm{p}$ Value & 0.578 & 0 & & \\
HPAT total & $\mathrm{N}$ & 120 & 120 & & \\
& Pearson's correlation & -0.026 & & & \\
& $\mathrm{p}$ Value & 0.775 & & & \\
& $\mathrm{~N}$ & 120 & &
\end{tabular}

Correlation coefficients correspond to results of Pearson's $r$ analysis.

${ }^{*} p<0.05$.

$\mathrm{tp}<0.001$.

HPAT, Health Professions Admissions Test; HPAT-Ireland section 1, logical reasoning and problem-solving; HPAT-Ireland section 2 , interpersonal understanding; HPAT-Ireland section 3, non-verbal reasoning; JSE, Jefferson Scale of Physician Empathy. 
some authors argue in favour of the implementation of empathy assessments during the medical school admission process ${ }^{46}$ the current data suggest no clear link between scores on a selection test, the HPAT-Ireland, which is designed to assess several skill domains including interpersonal skills and scores on a psychometric measure of empathy, at any point during medical education.

Acknowledgements For the permission to use the student-JSE in this research, we would like to acknowledge Jefferson Medical College. All rights are reserved. Jefferson, as the sole copyright holder, maintains the copyright for granting or declining permission for any additional use of any and all versions of the JSE.

Contributors DOS: substantial contributions to the conception or design of the work, acquisition and analysis of data. Agreement to be accountable for all aspects of the work in ensuring that questions related to the accuracy or integrity of any part of the work are appropriately investigated and resolved. JM: substantial contributions to the conception or design of the work. Final approval of the version to be published. PC: analysis and interpretation of data. SOF: substantial contributions to the conception or design of the work. CMPOT: analysis and interpretation of data, drafting the work and revising drafts. Final approval of the version to be published. AOS: drafting and revision of the work

Funding This research received no specific grant from any funding agency in the public, commercial or not-for-profit sectors.

Competing interests None declared.

Ethics approval Cork Research Ethics Committee.

Provenance and peer review Not commissioned; externally peer reviewed.

Data sharing statement Extra data can be accessed via the Dryad data repository at http://datadryad.org/ with the doi:10.5061/dryad.b551h.

Open Access This is an Open Access article distributed in accordance with the Creative Commons Attribution Non Commercial (CC BY-NC 4.0) license, which permits others to distribute, remix, adapt, build upon this work non-commercially, and license their derivative works on different terms, provided the original work is properly cited and the use is non-commercial. See: http://creativecommons.org/ licenses/by-nc/4.0/

(c) Article author(s) (or their employer(s) unless otherwise stated in the text of the article) 2017. All rights reserved. No commercial use is permitted unless otherwise expressly granted

\section{REFERENCES}

1. Stansfield RB, Schwartz A, O'Brien CL, et al. Development of a metacognitive effort construct of empathy during clinical training: a longitudinal study of the factor structure of the Jefferson Scale of Empathy. Adv Health Sci Educ Theory Pract 2016;21:5-17.

2. May W. Maintaining empathy in medical education. Med Teach 2013;35:977-8

3. Price S, Mercer SW, MacPherson H. Practitioner empathy, patient enablement and health outcomes: a prospective study of acupuncture patients. Patient Educ Couns 2006;63(1-2):239-45.

4. Squier RW. A model of empathic understanding and adherence to treatment regimens in practitioner-patient relationships. Soc Sci Med 1990;30:325-39.

5. Kim SS, Kaplowitz S, Johnston MV. The effects of physician empathy on patient satisfaction and compliance. Eval Health Prof 2004;27:237-51.

6. Beck RS, Daughtridge R, Sloane PD. Physician-patient communication in the primary care office: a systematic review. J Am Board Fam Pract 2002;15:25-38.

7. Gelhaus P. The desired moral attitude of the physician: (I) empathy. Med Health Care Philos 2012;15:103-13.

8. Costa MJ, Costa P. Nurturing empathy and compassion: what might the neurosciences have to offer? Med Educ 2016;50:281-2.

9. Hojat M, LaNoue M. Exploration and confirmation of the latent variable structure of the Jefferson scale of empathy. Int J Med Educ 2014;5:73.

10. Hojat M, Mangione S, Nasca TJ, et al. The Jefferson Scale of Physician Empathy: development and Preliminary Psychometric Data. Educ Psychol Meas 2001;61:349-65.
11. Hojat M, Gonnella JS, Mangione S, et al. Empathy in medical students as related to academic performance, clinical competence and gender. Med Educ 2002;36:522-7.

12. Ogle J, Bushnell JA, Caputi P. Empathy is related to clinical competence in medical care. Med Educ 2013;47:824-31.

13. McManus IC, Livingston G, Katona $\mathrm{C}$. The attractions of medicine: the generic motivations of medical school applicants in relation to demography, personality and achievement. BMC Med Educ 2006;6:11.

14. Pohl CA, Hojat M, Arnold L. Peer nominations as related to academic attainment, empathy, personality, and specialty interest. Acad Med 2011;86:747-51.

15. Hojat M, Michalec B, Veloski JJ, et al. Can empathy, other personality attributes, and level of positive social influence in medical school identify potential leaders in medicine? Acad Med 2015;90:505-10.

16. Hojat M, Zuckerman M, Magee M, et al. Empathy in medical students as related to specialty interest, personality, and perceptions of mother and father. Pers Individ Dif 2005;39:1205-15.

17. Gonçalves-Pereira M, Trancas B, Loureiro J, et al. Empathy as related to motivations for medicine in a sample of first-year medical students. Psychol Rep 2013;112:73-88.

18. Neumann M, Edelhäuser F, Tauschel D, et al. Empathy decline and its reasons: a systematic review of studies with medical students and residents. Acad Med 2011;86:996-1009.

19. Costa P, Magalhães E, Costa MJ. A latent growth model suggests that empathy of medical students does not decline over time. Adv Health Sci Educ Theory Pract 2013;18:509-22.

20. Learning objectives for medical student education--guidelines for medical schools: report I of the Medical School Objectives Project. Acad Med 1999;74:13-18.

21. Frank, J R. The CanMEDS 2005 physician competency framework. Better standards. Better physicians. Better care. Ottawa: The Royal College of Physicians and Surgeons of Canada, 2005.

22. Council IM. A Foundation for the Future: guidelines for medical schools and medical students on undergraduate professionalism. Dublin: Irish Medical Council, 2012.

23. Patterson F, Knight A, Dowell J, et al. How effective are selection methods in medical education? A systematic review. Med Educ 2016;50:36-60.

24. Plint S, Patterson F. Identifying critical success factors for designing selection processes into postgraduate specialty training: the case of UK general practice. Postgrad Med J 2010;86:323-7.

25. Patterson F, Ashworth V, Zibarras L, et al. Evaluations of situational judgement tests to assess non-academic attributes in selection. Med Educ 2012;46:850-68.

26. Kelly ME, Regan D, Dunne F, et al. To what extent does the Health Professions Admission Test-Ireland predict performance in early undergraduate tests of communication and clinical skills? an observational cohort study. BMC Med Educ 2013;13:68.

27. Report of the Working Group on Undergraduate Medical Education and Training. medical education in Ireland: a new direction. Dublin: Department of Health, 2006.

28. O'Flynn S, Mills A, Fitzgerald T. National research group evaluating revised entry mechanisms to medicine. interim report-School Leaver Entrants. Ireland: Council of Deans of Faculties of Medical Schools in Ireland, 2012.

29. Hojat M, Gonnella JS, Nasca TJ, et al. The Jefferson Scale of Physician Empathy: further psychometric data and differences by gender and specialty at item level. Acad Med 2002;77(10 Suppl):S58

30. Hojat M. Empathy in Patient Care: antecedents, Development, Measurement, and outcomes. SpringerLink, editor. New York, NY: Springer New York, 2007.

31. Quinn A, Corrigan MA, Broderick J, et al. A comparison of performances of consultant surgeons, NCHDs and medical students in a modified HPAT examination. Ir Med J 2010;103:172-3.

32. O'Flynn S, Mills A, Fitzgerald AP. Entry to medical school--the gender question. what has happened? Ir Med J 2013;106:230-2.

33. Tiffin PA, McLachlan JC, Webster L, et al. Comparison of the sensitivity of the UKCAT and A levels to sociodemographic characteristics: a national study. BMC Med Educ 2014;14:7

34. Puddey IB, Mercer A. Predicting academic outcomes in an Australian graduate entry medical programme. BMC Med Educ 2014;14:31.

35. Puddey IB, Mercer A, Carr SE, et al. Potential influence of selection criteria on the demographic composition of students in an Australian medical school. BMC Med Educ 2011;11:97.

36. Tiffin PA, Dowell JS, McLachlan JC. Widening access to UK medica education for under-represented socioeconomic groups: modelling the impact of the UKCAT in the 2009 cohort. BMJ 20121805;344:e18 05;344:e1805. e. 
37. Wilkinson D, Casey MG, Eley DS. Removing the interview for medical school selection is associated with gender Bias among enrolled students. Med J Aust 2014;200:96-9.

38. Hojat M, Vergare MJ, Maxwell K, et al. The Devil is in the third year: a longitudinal study of erosion of empathy in medical school. Acad Med 2009;84:1182-91.

39. Colliver JA, Conlee MJ, Verhulst SJ, et al. Reports of the decline of empathy during medical education are greatly exaggerated: a reexamination of the research. Acad Med 2010;85:588-93.

40. Davis $\mathrm{MH}$. Measuring individual differences in empathy: evidence for a multidimensional approach. J Pers Soc Psychol 1983;44:113-26.

41. Davis MH. Empathy: a social psychological approach. Boulder, CO, US: Westview Press, 1994.
42. Hojat M, Mangione S, Kane GC, et al. Relationships between scores of the Jefferson Scale of Physician Empathy (JSPE) and the Interpersonal reactivity index (IRI). Med Teach 2005;27:625-8.

43. Kelly ME, O'Flynn S. The construct validity of HPAT-Ireland for the selection of medical students: unresolved issues and future research implications. Adv Health Sci Educ Theory Pract 2017;22.

44. Costa P, de Carvalho-Filho MA, Schweller M, et al. Measuring Medical students' Empathy: exploring the underlying constructs of and associations between two widely used Self-Report Instruments in five countries. Acad Med 2017:92:860-867.

45. Hemmerdinger JM, Stoddart SD, Lilford RJ. A systematic review of tests of empathy in medicine. BMC Med Educ 2007;7:24.

46. Hojat M. Assessments of empathy in medical school admissions: what additional evidence is needed? Int J Med Educ 2014;5:p. 7-10. 